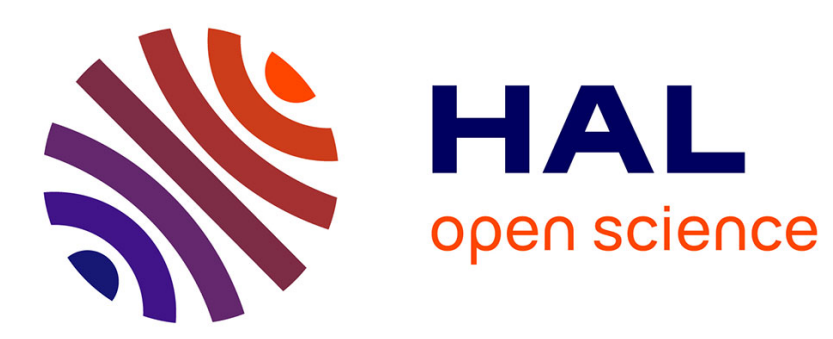

\title{
In situ experiments and seismic analysis of existing buildings. Part I: Experimental investigations
}

\author{
S. Hans, C. Boutin, E. Ibraim, P. Roussillon
}

\section{To cite this version:}

S. Hans, C. Boutin, E. Ibraim, P. Roussillon. In situ experiments and seismic analysis of existing buildings. Part I: Experimental investigations. EARTHQUAKE ENGINEERING \& STRUCTURAL DYNAMICS, 2005, 34 (12), pp.1513-1529. hal-00941380

\section{HAL Id: hal-00941380 \\ https://hal.science/hal-00941380}

Submitted on 3 Feb 2014

HAL is a multi-disciplinary open access archive for the deposit and dissemination of scientific research documents, whether they are published or not. The documents may come from teaching and research institutions in France or abroad, or from public or private research centers.
L'archive ouverte pluridisciplinaire HAL, est destinée au dépôt et à la diffusion de documents scientifiques de niveau recherche, publiés ou non, émanant des établissements d'enseignement et de recherche français ou étrangers, des laboratoires publics ou privés. 


\title{
In situ experiments and seismic analysis of existing buildings. Part I: Experimental investigations
}

\author{
S. Hans ${ }^{1, *, \dagger}$, C. Boutin ${ }^{1}$, E. Ibraim ${ }^{2}$ and P. Roussillon ${ }^{1}$ \\ ${ }^{1}$ Laboratoire Geomateriaux, Departement Genie Civil et Batiment, URA CNRS 1652, Ecole Nationale des \\ Travaux Publics de l'Etat, rue Maurice Audin, 69518 Vaulx-en-Velin Cedex, France \\ ${ }^{2}$ Department of Civil Engineering, University of Bristol, Queen's Building, University Walk Bristol, \\ BS8 $1 T R, U . K$
}

\begin{abstract}
SUMMARY
Recent results of in situ measurements and their interest for a seismic assessment of existing buildings are presented and analysed. The present paper (Part I) is devoted to the experimental programme. The response to ambient vibrations, harmonic excitation and shock loading is recorded on intact buildings but also after their structure or their vicinity was modified. These tests aim to identify the dynamic behaviour of ordinary intact buildings built in a conventional practise. Moreover, taking advantage of their demolition, it was possible (through these tests) to determine the actual influence of the light work elements, full precast facade panels, bearing masonry walls, and the presence of neighbouring joined buildings. These experiments realized on real buildings show that information gathered from ambient measurements provide reliable and efficient data of real interest for a clear understanding of the actual building behaviour. The advantage of integrating these data in the vulnerability assessment is presented and discussed in the next paper (Part II).
\end{abstract}

KEY WORDS: in situ test monitoring; existing buildings; ambient vibrations

\section{INTRODUCTION}

The seismic analysis of the existing buildings requires a particular attention for several reasons among which:

(i) a large amount of buildings were constructed without any consideration of seismic risk; in France for instance, the first regulations against seismic risks date from the

\footnotetext{
*Correspondence to: S. Hans, Laboratoire Geomateriaux, Departement Genie Civil et Batiment, URA CNRS 1652, Ecole Nationale des Travaux Publics de 1'Etat, rue Maurice Audin, 69518 Vaulx-en-Velin Cedex, France.

†E-mail: hans@entpe.fr

Contract/grant sponsor: French Ministry of Environment

Contract/grant sponsor: French Association of Earthquake Engineering (AFPS)
} 
70th. Thus, a small percentage of structures have been built with a design taking into account the seismic risk;

(ii) the necessity of establishing reliable diagnosis not only for strategic and public buildings but also for ordinary or industrial structures in order to identify vulnerable structures and to justify decisions to improve the structure.

Several methodologies, based mainly on statistical approaches, have been developed to assess the city seismic vulnerability [1-4]. As any statistical method, these approaches are reliable only if applied to a large number of buildings, i.e. at the urban scale, and only if sufficient amount of data is available-(un-)fortunately this is not the case for countries of low seismic activity. Therefore, when only a few number of seismic events are available, and when a given building is to be evaluated, these global vulnerability approaches are no longer relevant.

The level of uncertainty of any diagnosis on existing buildings is drastically increased by the lack of information (the architectural plans may exist but often the design plans are lost). However, this lack of information may be overcome by means of dynamic monitoring tests [5]. Thus, unlike the design methods that integrate data (known or estimated) to calculate and verify the acceptability of the structural dynamic behaviour, extracted data from simple experiments allow the identification of the leading phenomena that govern the behaviour of the real structure. Obviously, this approach does not claim to provide a very accurate modelling but, on the basis of experimental observations, the main goal is to propose simplified, though realistic, efficient models for a first diagnosis level. Following this idea, this study is an attempt to define a reliable methodology illustrated and discussed at the light of experiments on a few real buildings.

In this context, an experimental test programme using existing buildings before and during their demolition has recently been developed [6-8]. The aims of this study are threefold:

(i) to identify the dynamic behaviour of ordinary intact buildings built according to the design rules of common practise in France (where the shear walls are widely used);

(ii) to take advantage of their progressive demolition to obtain some qualitative and, where possible, quantitative answers of the actual influence on the modal characteristics of:

- the light work elements like secondary dividing walls ...;

- the full precast facade panels, the bearing masonry walls;

- the presence of neighbouring joined buildings;

(iii) to propose a practical criterion of interest for vulnerability diagnosis, based on both experimental data and simple beam modelling.

This study is presented in two subsequent papers. The present paper (Part I), divided into three sections, focuses on the experiments. The first section is devoted to the experimental procedure, data processing and studied building. In the second section, the experimental results obtained on intact buildings are presented and discussed. The third section deals with the observations and measurements gathered during progressive demolitions and their interpretation.

The following paper [9] highlights the interest of the experimental data to determine the seismic integrity threshold suited to a given structure. 


\section{MONITORING METHODS AND TESTED STRUCTURES}

Testing real structures offers the possibility to analyse phenomena that are difficult to reproduce in idealized laboratory experiments. In counter part, the tested structures are only partially known and the range of loading is limited. This section briefly presents the used in situ methods, the main structural characteristics of the tested buildings and the data processing.

\subsection{In situ monitoring methods}

In situ testing method consists in recording the responses of the structure on the bandwidth $0-50 \mathrm{~Hz}$ with synchronized accelerometers (with a sensibility of $5 \times 10^{-6} \mathrm{~g}$ ). To cover a large range of motion amplitude, three types of excitations are used to identify modal frequencies, shapes and damping ratios:

(i) Ambient vibrations: The method, initiated in the 70th $[10,11]$ knows actually large developments due to its simplicity $[12,13]$. The level of horizontal acceleration is of the order of $10^{-5} \mathrm{~g}$ at the bottom and $10^{-4} \mathrm{~g}$ at the building top. The density of probability of the random signals follows a Gaussian distribution so that the building responds to a white noise imposed motion.

(ii) Harmonic forcing: As in References $[14,15]$ or [16], an oscillator was used to identify the dynamic behaviour. Our device [17] induces a horizontal acceleration of about $10^{-4} \mathrm{~g}$ at the base and $10^{-3} \mathrm{~g}$ at the building top, i.e. around 10 times greater than ambient accelerations.

(iii) Shocks: Shock tests were realized by impacting the upper part of the building in the two main directions by means of an heavy mechanical shovel (usually used for demolition). The damage (when it appears) is localized in the very vicinity of the impact and outside this zone the structure remains entirely intact. To our knowledge, this test method was not proposed before though the use of a shovel can be simply implemented and tests easily repeated. Compared to the random ambient vibrations and harmonic oscillations, the short impulsive record is of larger magnitude with a pick acceleration of about $10^{-2} \mathrm{~g}$ even on the ground floor, i.e. thousand times greater than the ambient level.

Whatever the excitation is, the acceleration amplitudes are small enough not to move the structure's response beyond its elastic domain.

\subsection{Tested structures}

The buildings were located in Vaulx-en-Velin, suburbs of Lyon, France. At the time of testing, all the structures were in good condition, and their demolition was subsequent to a new urban planning policy. Built between 1970 and 1975, they are representative, from both engineering and architectural points of view, of the great number of modern urban buildings erected during that period. Some common characteristics of these tested buildings are

- a structural regularity in plan (with transverse and longitudinal plans of symmetry),

- a structural regularity in elevation (same structure of all the floors, no transparency on the ground floor), 
- the weak amount of steel reinforcement bars in the concrete elements (having the standard thickness of $15 \mathrm{~cm}$ ) and the very poor steel reinforcement in the precast panels.

2.2.1. The five tested buildings. A total number of eight structures have been intensively tested, however, only the results of five of them are presented in this paper. A general crosssectional view of typical floor plans and a picture for all these five structures are presented in Figures 1-3. The main characteristics for each building are described below.

- Building C, seven storeys, was erected using the 'tunnel casing' technique: the floors and transverse shear walls are made of reinforced concrete; the lengthwise bracing is mainly provided by the two full precast facade panels and the shaft walls of the lift.

- Buildings D, E, F, four storeys, were made of floors of reinforced concrete associated with external shear bearing walls in light parpen (masonry bricks) and internal shear bearing walls in heavy parpen (bricks); they were roughly placed on an axe parallel to one of their diagonal and separated by $5 \mathrm{~cm}$ gaps filled with polystyrene that runs only over a small part of the longitudinal facade.

- Building G, 15 storeys, presents floors and longitudinal and transversal shear walls in reinforced concrete; the facades are constituted by precast panels; a similar building of 10 storeys is located close to this building, across a $5 \mathrm{~cm}$ gap.
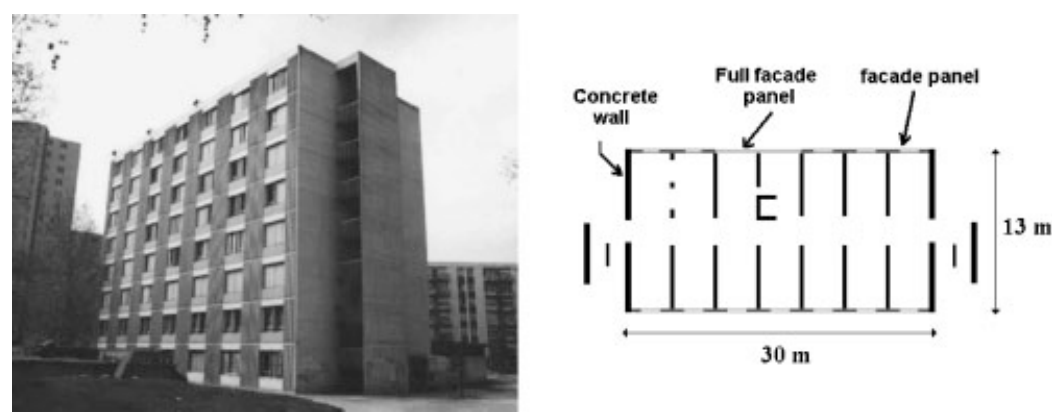

Figure 1. The building $\mathrm{C}$ and its typical floor plan view.
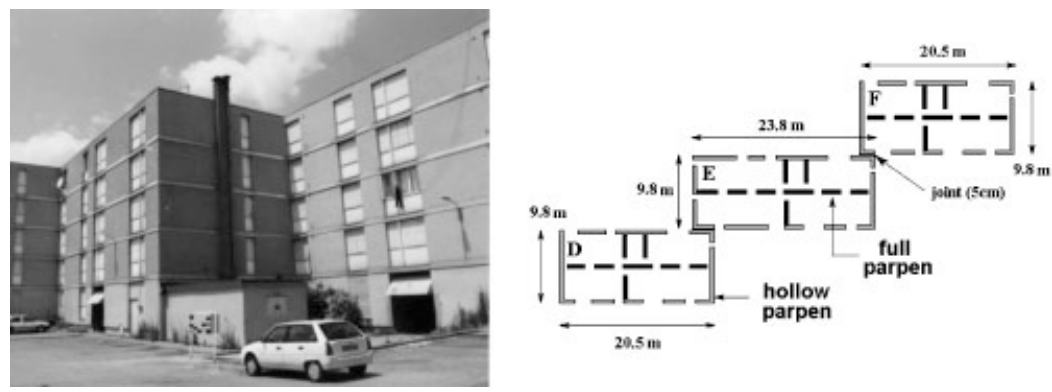

Figure 2. The buildings $\mathrm{D}, \mathrm{E}$ and $\mathrm{F}$ and their typical floor plan view. 

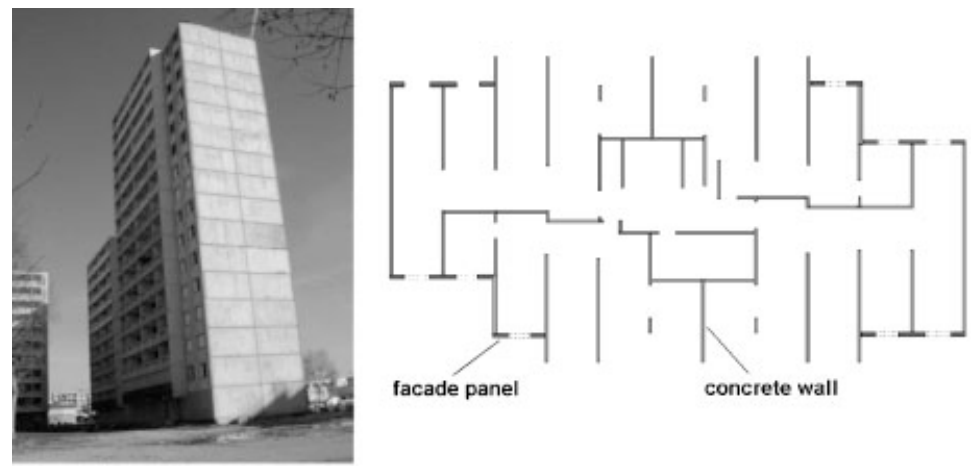

Figure 3. The building $\mathrm{G}$ and its typical floor plan view.

Table I. Dimensions and masses of tested buildings.

\begin{tabular}{lccccc}
\hline Building & $\mathrm{C}$ & $\mathrm{D}$ & $\mathrm{E}$ & $\mathrm{F}$ & $\mathrm{G}$ \\
\hline Length $L(\mathrm{~m})$ & 30.0 & 20.5 & 23.8 & 20.5 & 31.4 \\
Width $W(\mathrm{~m})$ & 14.0 & 9.8 & 9.8 & 9.8 & 13.4 \\
Height $H(\mathrm{~m})$ & 21.6 & 14.1 & 14.1 & 14.1 & 43.2 \\
$H / W$ ratio & 1.54 & 1.45 & 1.45 & 1.45 & 3.22 \\
$H / L$ ratio & 0.72 & 0.69 & 0.59 & 0.69 & 1.38 \\
$L / W$ ratio & 2.14 & 2.1 & 2.44 & 2.1 & 2.33 \\
Storey specific mass $\left(\mathrm{t} / \mathrm{m}^{3}\right)$ & 0.27 & 0.23 & 0.23 & 0.23 & 0.25 \\
Linear mass $(\mathrm{t} / \mathrm{m})$ & 114 & 46 & 53 & 46 & 110 \\
\hline
\end{tabular}

In Table Idimension and slender parameters of buildings $\mathrm{C}-\mathrm{G}$ are shown. The storey density and the building linear mass, deduced from the plans and the usual density value of constitutive materials, are also given.

2.2.2. Soil conditions. All the tested buildings are founded on shallow foundations. The soil is mixed gravel and consolidated clay deposits with good mechanical properties; a surface wave measurement indicates a shear wave velocity around $300 \mathrm{~m} / \mathrm{s}$ at $5 \mathrm{~m}$ depth.

\subsection{Processing of the records}

To extract information from the records, the theoretical framework of modal analysis is used. This approach is very well supported by the experimental results (see Section 3). In the general case, all the modes are simultaneously present in the structure response. Nevertheless as the eigenfrequencies of studied buildings were well separated and the damping weak (see Tables II and III)the contribution of the other modes at the frequency of a given mode can reasonably be neglected, at least for the few first modes.

Before presenting the processing techniques, let us precise the mechanical system investigated. 
Table II. Modal characteristics of building $\mathrm{C}$ in longitudinal direction.

\begin{tabular}{lccc}
\hline Mode number & Monitoring method & Frequency (Hz) & Damping (\%) \\
\hline Mode 1 & Ambient & 4.3 & 2.85 \\
& Free Osc. & 4.25 & 2.4 \\
& Harmonic & 4.19 & 2.6 \\
Mode 2 & Shock & 4.18 & 4 \\
& Ambient & 13.4 & 3.5 \\
Mode 3 & Shock & 12.8 & 4 \\
& Ambient & 23 & 4 \\
& Shock & 22.5 & 3.8 \\
\hline
\end{tabular}

Table III. Modal characteristics of building G.

\begin{tabular}{lcccccc}
\hline & & \multicolumn{2}{c}{ Longitudinal direction } & & \multicolumn{2}{c}{ Transversal direction } \\
\cline { 3 - 3 } Mode number & Monitoring method & $\begin{array}{c}\text { Frequency } \\
(\mathrm{Hz})\end{array}$ & $\begin{array}{c}\text { Damping } \\
(\%)\end{array}$ & & $\begin{array}{c}\text { Frequency } \\
(\mathrm{Hz})\end{array}$ & $\begin{array}{c}\text { Damping } \\
(\%)\end{array}$ \\
\hline \multirow{2}{*}{ Mode 1} & Ambient & 2.08 & 2.5 & & 1.56 & 1.3 \\
& Free Osc. & 1.96 & 2.6 & & 1.49 & 1.5 \\
\multirow{2}{*}{ Mode 2} & Harmonic & 1.94 & 2.3 & & 1.48 & 1.5 \\
& Ambient & 7 & 2.5 & & 6.6 & 4 \\
\multirow{2}{*}{ Mode 3} & Free Osc. & 6.75 & 2.6 & & 6.26 & 2.2 \\
Mode 4 & Harmonic & 6.73 & 2.4 & & 6.17 & 2.3 \\
\hline
\end{tabular}

2.3.1. Structure-soil system and structure on fixed basement. The in situ measurements naturally lead to the modal characteristics of the structure coupled with the soil. However, when the soil presents good characteristics, as in the case of the site of Vaulx-en-Velin, a weak contribution of the soil-structure (SS) interaction might be expected and therefore, the modal parameters of the structure coupled with the soil close to those of the structure lying on a rigid motionless basis, at least for the first modes. Nevertheless, when possible, it is interesting to derive the own modal characteristics of the structure on fixed base (SB), corresponding to the intrinsic properties of the structure.

Assuming that the building base is infinitely rigid, the SS system is composed of two coupled sub-systems, one constituted by the soil, the other by the structure on rigid basement (SB). In the case of ambient vibrations due to soil motions, a weak SS interaction means that the base motion is almost identical to the incident motion. Thus, it can be considered that the structure motions, observed in the non-Galilean frame attached to the base, define the SB transfer functions. Consequently, the intrinsic behaviour of SB structure is deduced by suppressing the rigid body motion induced by the base motion.

In case of harmonic excitation and impact loading, it is expected that the base motion be mainly due to the SS interaction; therefore, the identification of the SB behaviour from the SS behaviour would require more sophisticated derivations. 
2.3.2. Processing techniques. The signals are processed with several usual technique performed in both spectral and time domain.

Spectra using fast Fourier transform (FFT) for ambient vibrations (with smoothing), free oscillations and shocks have been calculated. With a very good precision, the modal frequencies and shapes of the coupled SS system are simply deduced by peak-picking. The damping ratio is assessed from the pass-band width. The same procedure applies for the calculation of the modal transfer functions of the structure (SB).

The process in the time domain is specific for each kind of signal. Random signals are first filtered around each modal frequency (identified on the spectrum), then the autocorrelation functions are determined. From these, the mode shape is deduced by extracting the extrema and the modal damping ratio is derived very accurately from the logarithmic decrement. Harmonic responses are exploited classically. Eigenfrequencies are identified from the maximum sweep response, mode shapes from the amplitudes at the eigenfrequencies and damping ratio from the sweep response bandwidth. Finally some shocks responses were processed using Cauchy wavelet [18] in order to reveal the weak non-linearity effects when they occur.

\section{RESULTS CONCERNING INTACT STRUCTURES}

In this study, the modal analysis approach is systematically used. This choice is largely justified by the experimental facts. Among them, the following can be mentioned:

- the presence of sharp peaks in the frequency response spectra which indicates a notable response amplification at those frequencies;

- the fact that those frequencies are identical in any point of the structure which proves that, actually, the whole structure is affected by the same oscillation;

- very similar results are obtained with multi-type loadings (random, harmonic, shock) having very different levels of amplitudes (ranging over four decades) which illustrates the characteristic feature of (quasi-)linear systems;

- that, systematically, the $n$th modal shape has $n$ fix levels.

\subsection{Identification of modal characteristics}

As an example, some experimental modal frequencies and damping ratio for buildings $\mathrm{C}$ and $\mathrm{G}$ are gathered in Tables II and III and the corresponding modal shapes are presented in Figures 4 and 5. It is observed that results given by different vibration methods all agree. This is a general result which was systematically observed for all the buildings tested.

These experimental findings confirm that from small amplitudes of ambient vibrations to significantly larger amplitudes reached by employing shocks, the structures respond systematically by following the same quasi-elastic behaviour [11]. As a consequence, the rather simple ambient measurements is sufficient to identify the structure's behaviour for the whole quasi-elastic domain. 


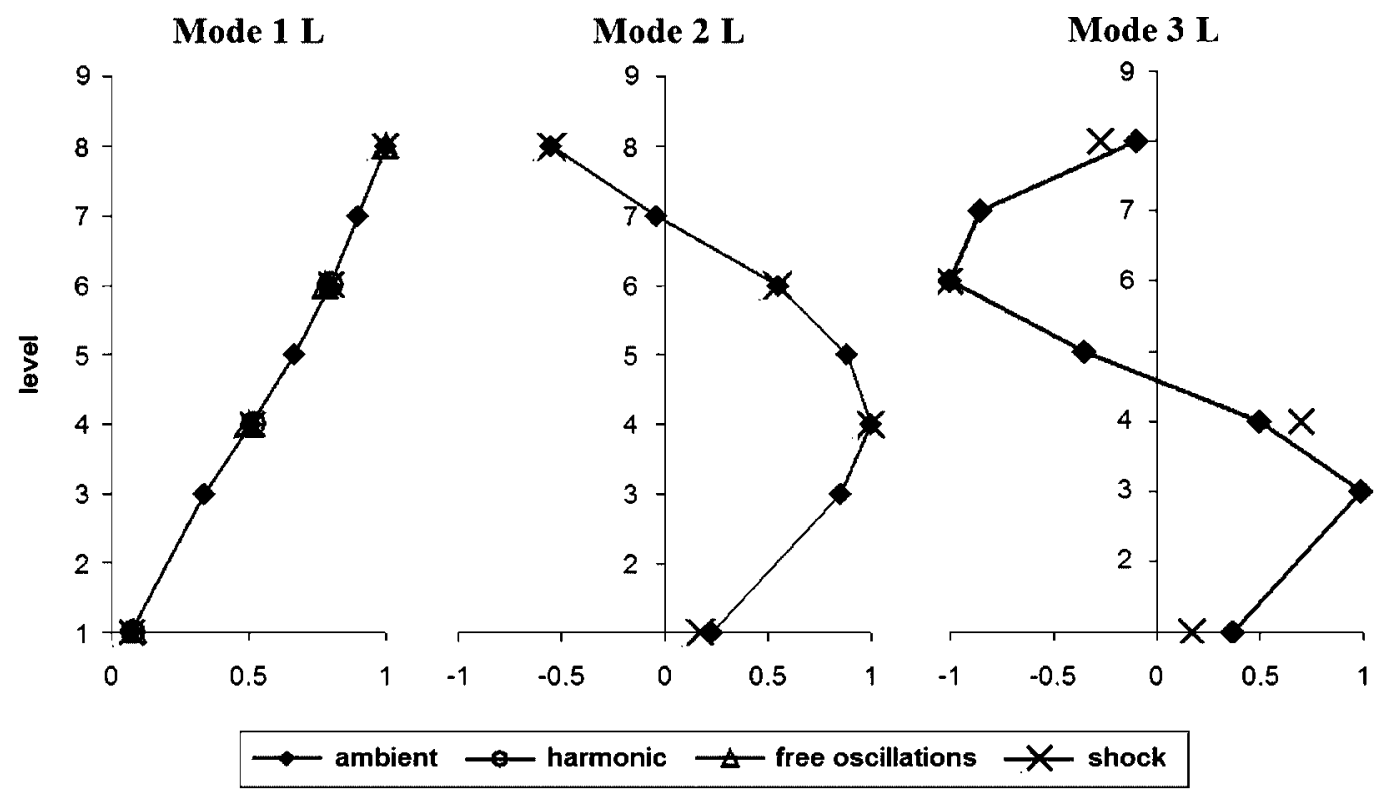

Figure 4. Mode shapes of building $\mathrm{C}$ in longitudinal direction.

\subsection{Weak non-linear effects}

The in situ tests bring to the fore a low non-linearity in responses of the buildings in function of the amplitude of the solicitation. Systematically the identified eigenfrequencies tend to decrease from ambient to shocks tests (Tables II and III). Nevertheless, this fall is very small since between 2 and 5\% while excitation amplitude wins a factor thousand (from about $10^{-5}$ to $10^{-2} \mathrm{~g}$ ). The variation on damping is not so clear and no modification of modal shapes seems to occur. This phenomenon has already been observed in the past by different authors (see for instance References [15, 19]).

A more sophisticated study has been realized with wavelet analysis on shocks tests to precise the importance and the origin of this non-linear effect. This provides instantaneous characteristics of a transient signal, i.e. in function of the time, the modal frequencies and modal amplitudes from which the associated damping or shapes can be deducted. As a shock response ranges from high level at the beginning to the ambient level at the end, a good overview can be obtained. Figure 6 shows a shock response of building $C$ and its wavelet representation in the plan time-frequency. The first three vibration modes (respectively, between 4.1 and $4.3 \mathrm{~Hz}, 12.8$ and $13.5 \mathrm{~Hz}$ and around $22.5 \mathrm{~Hz}$ ) and their duration (linked to their damping) are clearly depicted. This analysis shows a light decrease of the eigenfrequencies and a light increase of the modal damping with the increase of amplitude response. This softening behaviour is similar to soil behaviour. Hence it seems reasonable to localize the origin of this non-linearity in the soil foundation through SS interaction phenomena. It has nevertheless to be underlined that the modal shapes do not present any variation. The observed variations of parameters are sufficiently limited (never more than $7 \%$ ) to be neglected in first approximation. 
Mode 1 L

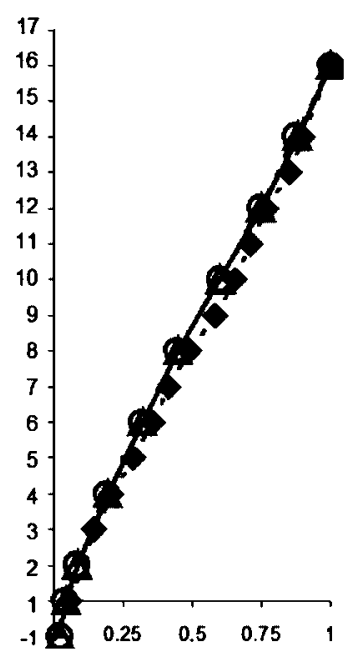

Mode 1 T

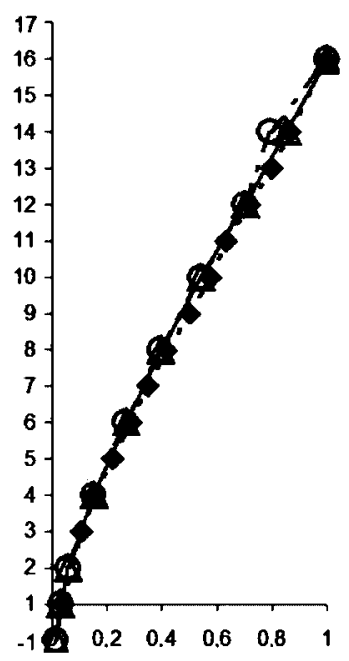

Mode 2 L

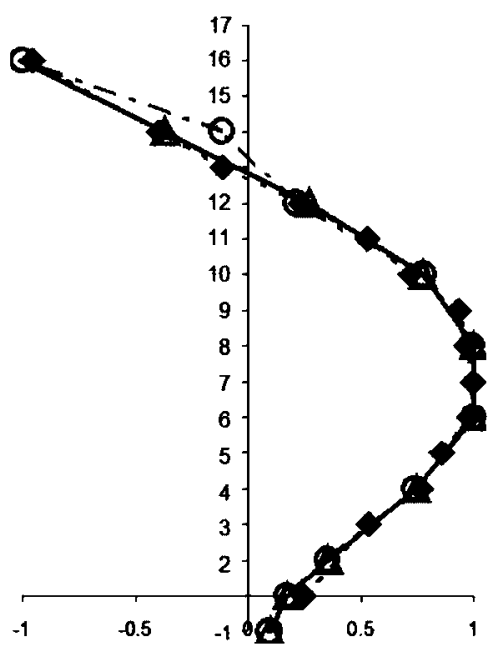

Mode 2 T

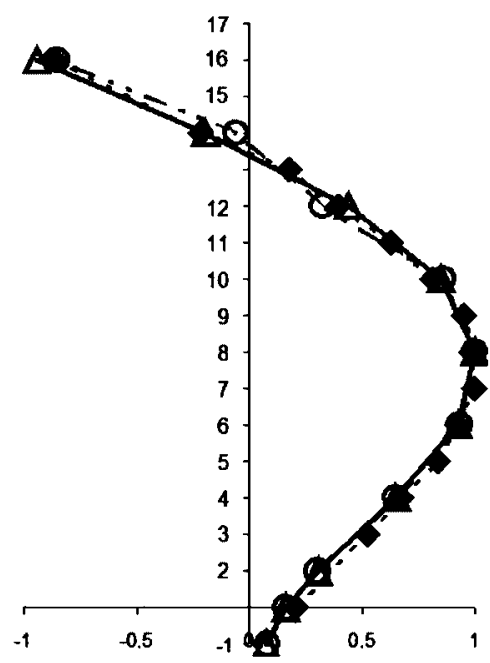

Modes 3-4 L

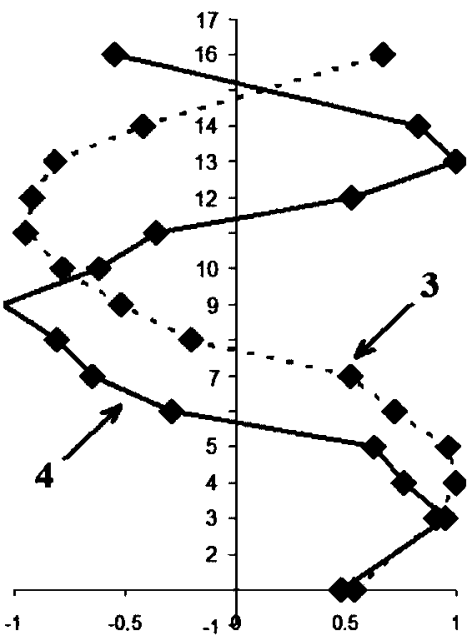

\section{Mode 3 T}

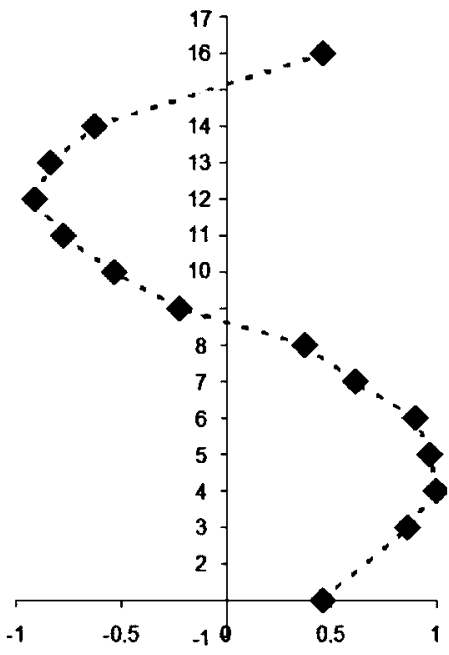

ambient $-\mathcal{O}$ harmonic $\perp$ free oscillations

Figure 5. Mode shapes of building G.

\subsection{SS interaction}

The SS interaction is now examined. The modal shapes presented in Figures 4 and 5 are related to the SS system (Section 2.3.1) that includes the soil participation in the dynamics. The displacement of the base is clearly visible, increasing from the first to higher modes. 

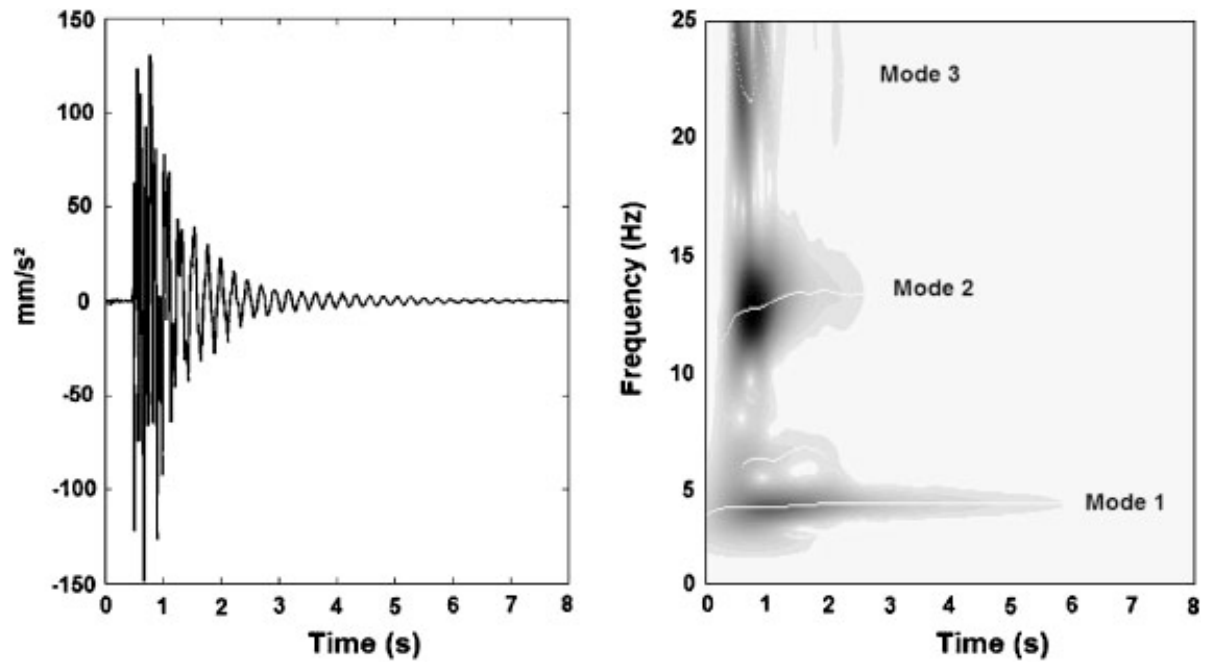

Figure 6. Wavelet analysis of a shock test on building C (longitudinal direction).

Table IV. Soil-structure interaction-comparison between SS and SB characteristics.

\begin{tabular}{|c|c|c|c|c|c|}
\hline \multirow[b]{2}{*}{ Direction } & \multirow[b]{2}{*}{ Mode } & \multicolumn{2}{|c|}{ Building $\mathrm{C}$} & \multicolumn{2}{|c|}{ Building G } \\
\hline & & $\begin{array}{l}\text { Soil-structure } \\
\text { (SS) }\end{array}$ & $\begin{array}{c}\text { Structure on } \\
\text { fixed base (SB) }\end{array}$ & $\begin{array}{l}\text { Soil-structure } \\
\text { (SS) }\end{array}$ & $\begin{array}{c}\text { Structure on } \\
\text { fixed base (SB) }\end{array}$ \\
\hline \multirow[t]{3}{*}{ Longitudinal } & 1 & 4.32 & 4.45 & 2.08 & 2.15 \\
\hline & 2 & 13.5 & 14.1 & 7 & 7.25 \\
\hline & 3 & 23 & 23.6 & 12.8 & 14 \\
\hline \multirow[t]{3}{*}{ Transversal } & 1 & 4.5 & 4.66 & 1.56 & 1.56 \\
\hline & 2 & - & - & 6.6 & 6.65 \\
\hline & 3 & - & - & 13.5 & 14 \\
\hline
\end{tabular}

According to the procedure given in Section 2.3.1, the characteristics of the SB are deduced and compared in Table IVand Figure 7 with SS modal characteristics for buildings $\mathrm{C}$ and G. As expected, the SS eigenfrequencies are smaller than SB ones, because of the softness induced by the soil. Moreover, the differences grow from the first to the higher modes. This is consistent with the increase of the modal rigidity of the structure with modal number, leading in turn to increase the SS interaction:

- For the first and second modes, the modal structure rigidity is too low to initiate significant interaction with the soil, and effectively there are small differences between SB and SS modal characteristics.

- For higher modes, the modal structure rigidity grows quickly and larger modifications of the modal characteristics appear. 


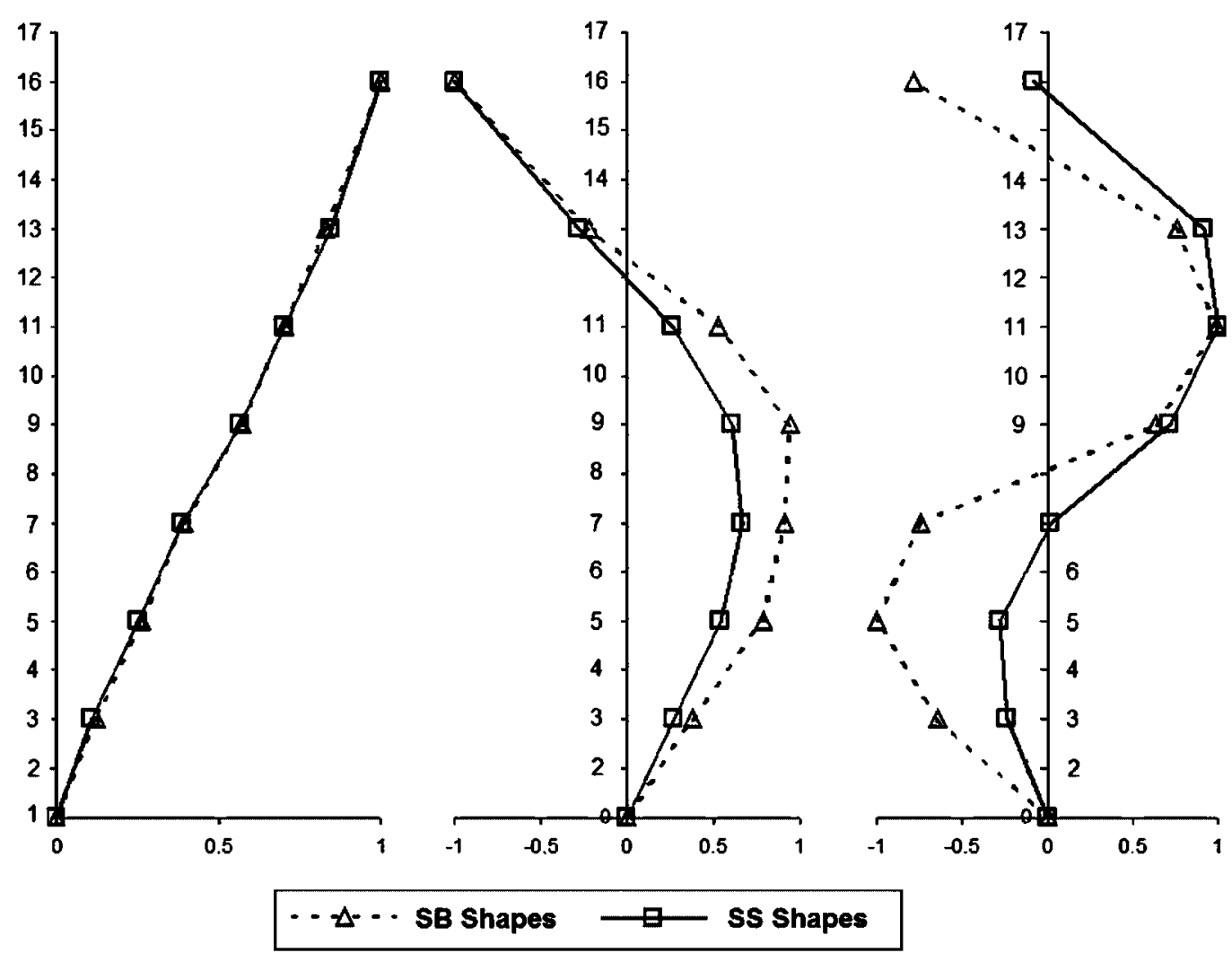

Figure 7. Comparison of SB and SS modal shapes for building G (the base motions being nullified).

It is worth mentioning that, for studied buildings, this effect is limited (less than $5 \%$ for the eigenfrequencies), which means that, from a seismic vulnerability point of view, SS interaction does not modify significantly the seismic behaviour.

\section{EXPERIMENTS ON MODIFIED STRUCTURES}

Measurements on real buildings may be actually of interest for seismic assessment, provided that they represent the effective dynamic behaviour before significant structural damages. This question is nevertheless difficult to address theoretically because of the lack of reliable information for modelling parasite phenomena that may modify the modal characteristics. Thus experiments dedicated to the analysis of these perturbation effects (like for instance due to the presence of light work elements,...) provide qualitative, or when possible, quantitative estimates. For this reason, in addition to the experiments on intact structures, tests were also performed after modifying the buildings or their immediate vicinity. If general conclusions 
cannot be drawn from the particular studied cases, the trends will nevertheless be useful for number of buildings presenting similar configurations.

\subsection{Effect of light work elements}

To what extent can the presence of light work elements in the building influence its modal characteristics? The additional mass of these elements can reasonably be estimated to about $5 \%$ of the mass of the structure. The true difficulty is mainly the additional rigidity brought by the light elements well connected to the structure, its direct quantification being almost impossible because of the large number of unknown parameters.

The demolition of the building $G$ has given the possibility to investigate on this aspect. As the concrete was intended to be recycled after demolition, it was imperative to avoid any contamination with the other construction materials. For this reason, the light elements such as the secondary dividing walls in plaster or bricks (thickness of 5-7 cm), the windows and their aluminium frames, the doors and doorways in wood and steel, were taken off before beginning the demolition of the 'naked' concrete structure.

Ambient vibrations measurements were performed on the cleared structure. The comparison with the spectra obtained for the intact building is presented in Figure 8. It appears that removing all the non-structural elements induces a slight (but clearly measurable) decrease of eigenfrequencies of about $2-4 \%$. This means that, in the considered case, the rigidity effect is more significant than the mass effect.

From this experiment and with these kind of very common buildings equipments, the presence of these non-structural elements can be considered to increase the shear and bending stiffness by about $5 \%$. This effect can therefore be neglected in a first analysis.

\subsection{Importance of masonry parpen walls}

The role of the masonry parpen wall in the modal behaviour is not always clear, essentially because the material properties are not very well known, and the quality of the connections with the other structural elements is questionable.

In building $\mathrm{F}$, the influence of walls made of light parpen was investigated in the following way. The entire wall (i.e. for the four storeys) constituting the south facade was demolished,
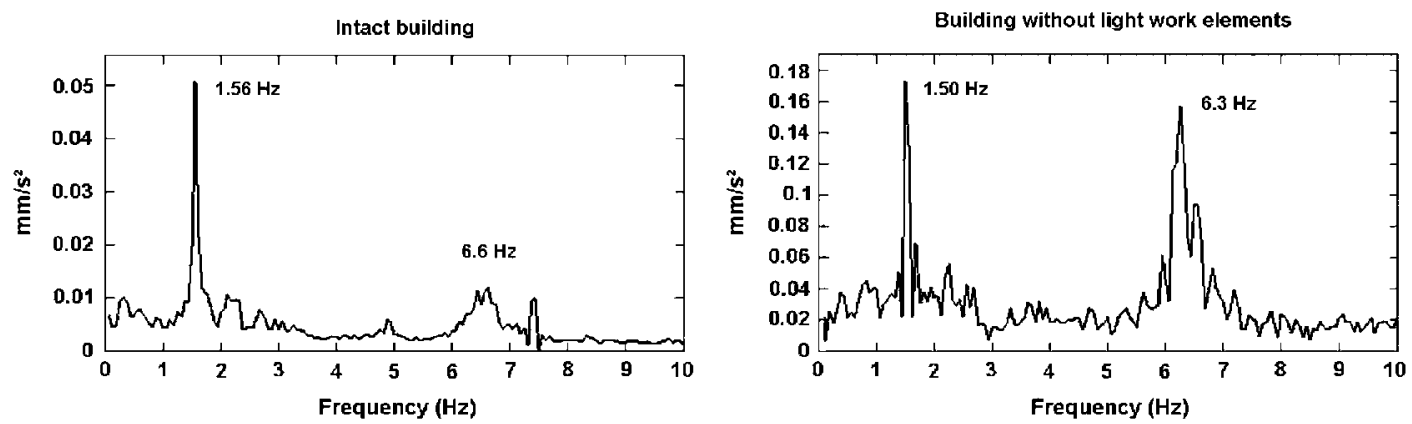

Figure 8. Examples of Fourier transforms of ambient vibrations measurements realized on building G before and after the removal of light work elements (transverse direction). 
leaving the rest of the building unmodified (Figure 9). Then free oscillations were recorded after impacts in the North-South and East-West directions. Note that the destruction of the wall broke the quasi-symmetry of the intact building, so that a pure E-W translation mode is no longer possible. Figure 10 shows the comparison of the responses spectra for the intact and modified building.

In the E-W direction (shear direction of the destroyed wall), a drastic reduction of the eigenfrequency from 5.15 to $4.5 \mathrm{~Hz}$ is observed. This leads to a rough assessment of the wall contribution to about a quarter of the storey rigidity. This estimate is consistent with the reduction of the total length of the E-W shear walls.

In the $\mathrm{N}-\mathrm{S}$ direction (out-of-plane bending direction of the destroyed wall), the frequency of the main peak remains the same, meaning that the out of plane bending stiffness is negligible in regard to the shear rigidity of the $\mathrm{N}-\mathrm{S}$ walls (the emergence of the secondary peak at the same frequency $(4.5 \mathrm{~Hz})$ as in the $\mathrm{E}-\mathrm{W}$ direction may result either from the coupling between both directions or from an imperfect direction of the impact).

Finally, those experiment on intact and modified building $\mathrm{F}$ enables, from a simple discrete shear beam model, to assess the equivalent modulus of the heavy and light parpen, respectively, to $E_{\mathrm{FP}} \approx 2.7 \mathrm{GPa}$ and $E_{\mathrm{HP}} \approx 1.5 \mathrm{GPa}$. These values, 10 times smaller than the values for concrete, are consistent with those given in the literature. As a conclusion, despite the presence of internal walls of heavy parpen, the contribution of the light parpen walls (in their shear direction) is very significant, and cannot be neglected. This result is of first importance for framed building with masonry infill. This conclusion is also supported by a large number of post-earthquake reports, mentioning that the absence of infills at the ground level artificially creates a critical 'transparent' storey.

\subsection{Role of plain precast facade panels}

Precast facade panels are widely used in recent buildings. It is generally assumed that their connection with the concrete structure is sufficiently good to consider that the full panels (i.e. without large opening for windows) may participate to the horizontal strength of the building. This point was checked by means of a step-by-step demolition realized on the

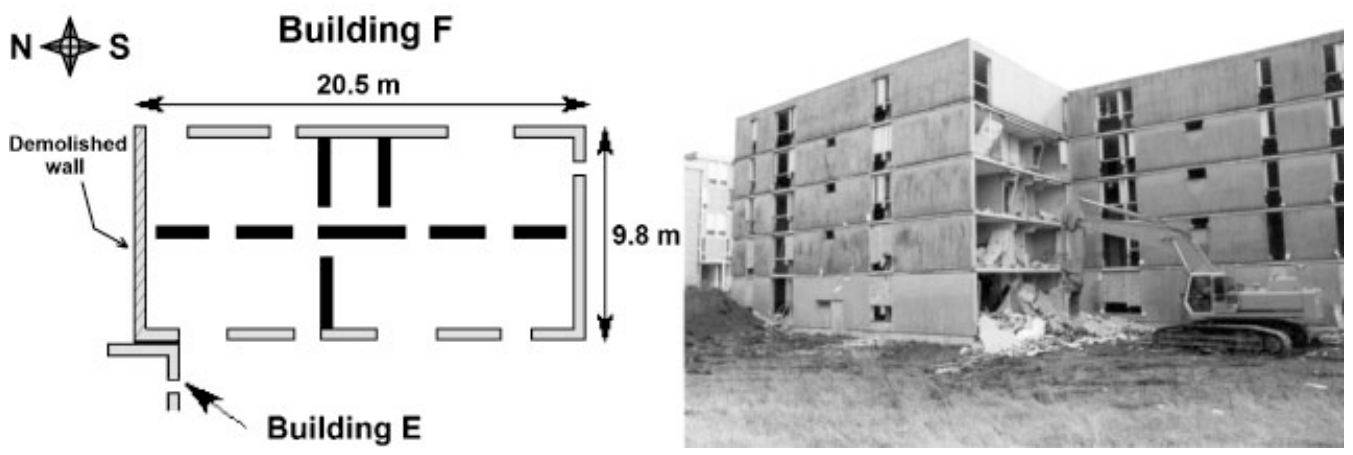

Figure 9. Modification of building $\mathrm{F}$ - the wall has been demolished from the base to the top of the building. 

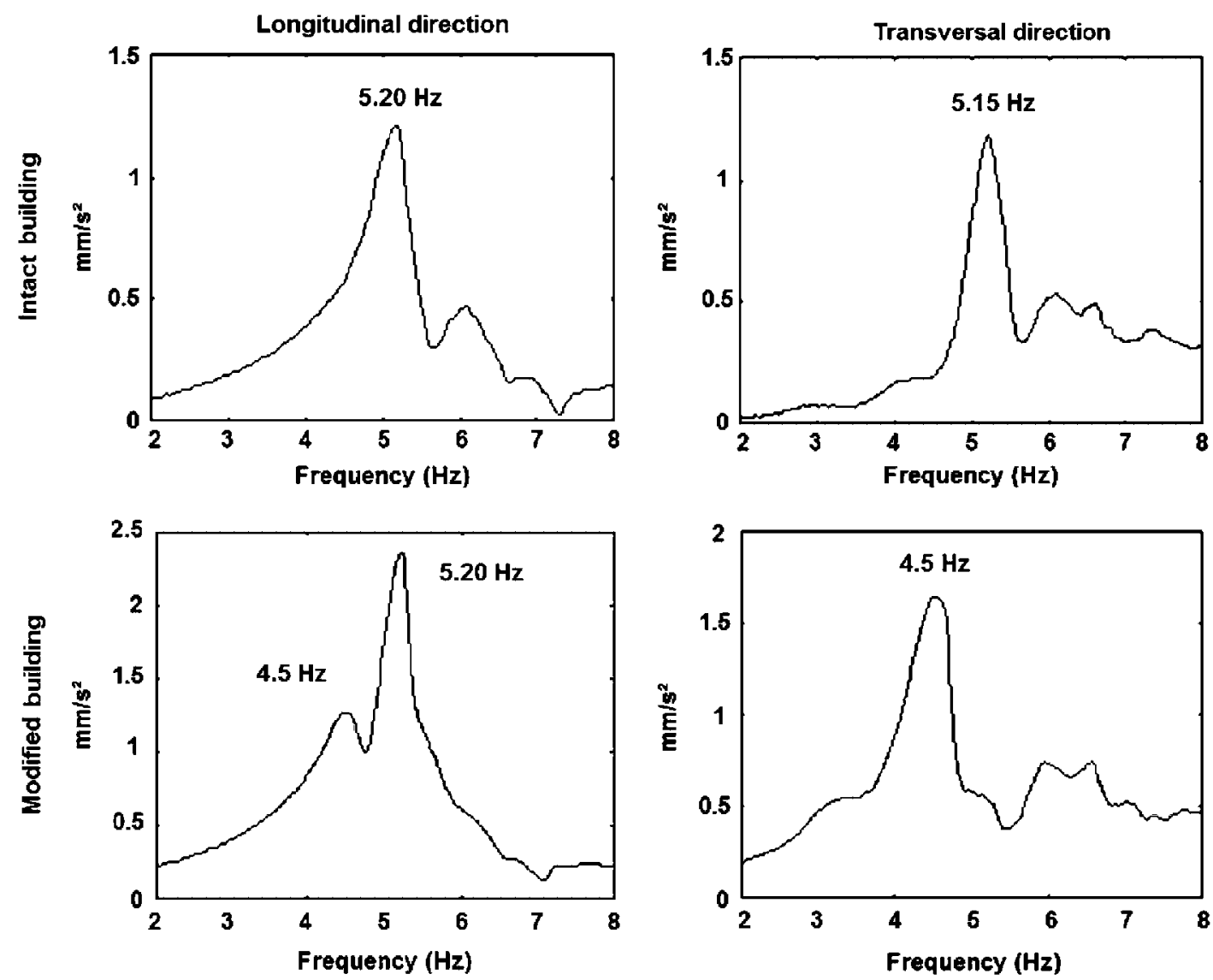

Figure 10. Comparison of the spectrum responses for the intact and modified building F.

building $\mathrm{C}$ which included two full panels by storey. At first, at the ground level, a panel of the longitudinal North-West facade was removed using the mechanical shovel (taking care not to damage the rest of the building). Then a shock was applied in the longitudinal direction (shear direction of the removed panel) and the free oscillations recorded. The same procedure was reproduced twice for the two plain panels at the second level.

The experimental results recorded in the four states (intact and -1 or -2 or -3 removed panels) are presented in Figure 11 where a zoom on the spectrum around the first longitudinal eigenfrequency is plotted. A slight but measurable regular decrease of the frequency clearly appears, although the modifications only affect two of the eight storeys. By a simple modelling based on discrete shear beam, one deduces that the contribution of the two panels to the storey shear rigidity lies in between 20 and $25 \%$.

This confirms that full panels in their shear direction are not to be neglected to understand the modal behaviour. Let us mention that, as for the parpen walls, the panels are only slightly reinforced and would not present any ductility under seismic loading. 
Facade

\begin{tabular}{|c|c|c|c|c|c|c|}
\hline$\square$ & $\square$ & $\square$ & 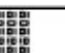 & & $\square$ & $\square$ \\
\hline$\square$ & $\square$ & $\square$ & 艚 & & $\square$ & $\square$ \\
\hline$\square$ & $\square$ & $\square$ & 俩整 & & $\square$ & $\square$ \\
\hline$\square$ & $\square$ & $\square$ & 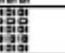 & & $\square$ & $\square$ \\
\hline$\square$ & $\square$ & $\square$ & H. & & $\square$ & $\square$ \\
\hline$\square$ & $\square$ & $\square$ & 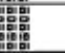 & & $\square$ & $\square$ \\
\hline$\square$ & $\square$ & $\square$ & 3 & 2 & $\square$ & $\square$ \\
\hline$\square$ & $\square$ & $\square$ & & 1 & $\square$ & $\square$ \\
\hline
\end{tabular}

0.2

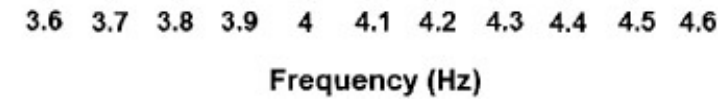

Figure 11. Evolution of first longitudinal eigenfrequency during the successive removals of full precast panels on the building $\mathrm{C}$.

Table V. Structure-soil-structure interaction - decreasing of fundamental frequency of building D during the demolition of neighbouring buildings $\mathrm{E}$ and $\mathrm{F}$.

\begin{tabular}{lcccc}
\hline Building(s) in presence & $\begin{array}{c}\text { D-E-F } \\
\text { intact }\end{array}$ & $\begin{array}{c}\text { D-E intact } \\
\text { F demolished }\end{array}$ & $\begin{array}{c}\text { D intact } \\
\text { E-F demolished }\end{array}$ & $\begin{array}{c}\text { Total } \\
\text { decreasing } \\
(\%)\end{array}$ \\
\hline Longitudinal first frequency of D (Hz) & 5.6 & 5.4 & 5.08 & 9 \\
Transversal first frequency of D (Hz) & 5.65 & 5.47 & 5.35 & 5 \\
\hline
\end{tabular}

\subsection{Influence of neighbouring joined buildings}

In urban area the buildings are often very close to each other. Nevertheless, in general, their possible dynamic mutual influences are not taken into account. This aspect was investigated in the group of the three similar buildings D, E, F by this way: the ambient vibrations of the intact building $\mathrm{D}$ was recorded in presence of buildings $\mathrm{F}$ and $\mathrm{E}$, then again after demolishing $\mathrm{F}$, and finally after both $\mathrm{F}$ and $\mathrm{E}$ buildings were completely destroyed.

The resulting modifications of the first eigenfrequency are given in Table V. In both directions, the successive suppression of neighbouring buildings induced a systematic decreasing of the frequencies. The differences are not negligible and can reach $10 \%$ in the more significant case. It should be noted that the magnitude of the ambient motion is very small compared to the thickness of the structural joints (which concerns only a small part of the facade) which therefore do not play any role in the dynamics. Thus the origin of the buildings coupling has to be found in the transmission of motions and stresses throughout the soil.

The modelling of this dynamic structure-soil-structure interaction phenomenon would require numerical approaches. Nevertheless, a first explanation consistent with the measurements 
can be proposed. Let us consider two identical joined buildings. The soil stiffness imposes the differential motion of their rigid foundation to be negligible. Therefore, both buildings will respond to the soil vibrations almost as if they were lying on an unique common foundation. In comparison with the same single isolated building, the only difference lies in the fact that, proportionally, the rocking impedance is smaller for the isolated building. Consequently, the single building eigenfrequencies should be smaller than the two joined buildings eigenfrequencies.

This experiment tends to show that the mutual influence, namely the structure-soil-structure interaction, may play a role, especially for close buildings presenting almost the same features (and eigenfrequency). Nevertheless further experimental investigations should be carried on before generalizing this conclusion.

To conclude this section, the presence of light work elements or joined buildings may interfere when measuring the modal characteristics of existing building using low level acceleration. However, the experimental estimations of those effects show that they should be considered as perturbation and they cannot modify drastically the building dynamic. Inversely, the parpen walls or full precast facade panels play a significant role so that they have to be considered to understand the dynamic behaviour of a building.

\section{CONCLUSIONS}

The lessons drawn from this experimental program concern both the monitoring methods and the dynamic behaviour of usual buildings.

The consistent agreement systematically observed on real buildings when using ambient, harmonic and shock excitation methods deserves to be emphasized for two main reasons. First, the stability and the consistency of the results prove the robustness and the reliability of information collected through these in situ methods. Second, it demonstrates that almost the same quasi-elastic behaviour remains valid on a wide range of acceleration levels covering the ambient level (around $\left.10^{-5} \mathrm{~g}\right)$ up to the shock level $\left(10^{-2} \mathrm{~g}\right.$ for the tested buildings).

The comparative tests performed on intact and modified structures enables to identify and quantify the leading and negligible phenomena that may influence the actual quasi-elastic behaviour. It is shown that full precast facade panels or masonry shear walls do have a significant role in the building response. On the contrary, the light work elements, the effect of neighbouring structure, may exist but can be neglected in a first approximation. As those effects are poorly documented, their quantification in some particular cases should be useful in a number of similar situations. Moreover, these investigations point out the elements of the structure that have actually to be considered in the building behaviour before significant damage. This is a key point before intending to integrate in situ data in a diagnosis procedure.

This study tends to show that ambient vibrations measurements, which can easily be performed, are a very efficient method to overcome the lack of information on most of existing buildings. It provides data that may be useful to establish a draft seismic vulnerability analysis. As a matter of fact, the quasi-elastic behaviour is known to induce a dynamic amplification near eigenfrequencies, that leads to the onset of structural damages during earthquakes. In the subsequent paper [9] the advantages of using these data in the diagnosis of existing structures will be extensively discussed. 
This research was supported by the French Ministry of Environment and the French Association of Earthquake Engineering (AFPS).

\section{REFERENCES}

1. Benedetti D, Benzoni G, Parisi MA. Seismic vulnerability and risk evaluation for old urban nuclei. Earthquake Engineering and Structural Dynamics 1988; 16:183-201.

2. Spence RJS, Coburn AW, Pomonis A. Correlation of ground motion with building damage: the definition of a new damage-based seismic intensity scale. Acts of the Tenth World Conference on Earthquake Engineering, 1992, Madrid, Spain.

3. ATC 40. Seismic evaluation and retrofit of concrete buildings. Applied Technology Council, Redwood City, California, 1996.

4. RISK-UE. An advanced approach to earthquake risk scenarios with applications to different european towns, Projet Europeen, EVK4-CT-2000-00014, 2003.

5. Hudson DE. Dynamic tests of full-scale structures. Earthquake Engineering. Prentice-Hall: Englewood Cliffs, NJ, 1970: 127-149.

6. Boutin C, Hans S. Using buildings to be demolished for vulnerability assessment. Acts of the Eleventh European Conference on Earthquake Engineering, Paris, 1998.

7. Boutin C, Hans S, Ibraim E. Pour une approche experimentale de la vulnerabilite sismique. Revue Francaise de Genie Civil 2000; 4(6):683-714.

8. Hans S. Auscultation dynamique de batiments et modelisation par homogeneisation - contribution a l'analyse de la vulnerabilite sismique. Ph.D. Thesis, ENTPE-INSA, Lyon, 2002.

9. Boutin C, Hans S, Ibraim E, Roussillon P. In situ experiments and seismic analysis of existing buildings. Part II: seismic integrity threshold. Earthquake Engineering and Structural Dynamics 2005; 34.

10. Stubbs IR, MacLamore VR. The ambient vibration survey. Proceedings of Fifth World Conference on Earthquake Engineering, Rome, Italy, 1973.

11. Trifunac MD. Comparisons between ambient and forced vibrations experiments. Earthquake Engineering and Structural Dynamics 1972; 1:133-150.

12. Ivanovic SS, Trifunac MD, Todorovska MI. Ambient vibration tests of structures - a review. Bulletin of Indian Society of Earthquake Technology: Special Issue on Experimental Methods, December 2000.

13. Farsi MN. Identification des structures de Genie Civil a partir de leur reponse vibratoire. Vulnerabilite du bati existant. These Universite Joseph Fournier, Grenoble, December 1996.

14. Englekirk RE, Matthiesen RB. Forced vibration of an eight-story reinforced concrete building. Bulletin of the Seismological Society of America 1967; 57(3):421-436.

15. Jennings PC, Kuroiwa JH. Vibration and soil-structure interaction tests of a nine-story reinforced concrete building. Bulletin of the Seismological Society of America 1968; 58(3):891-916.

16. Petrovski J, Jurukovski D, Paskalov T. Dynamic properties of fourteen-story reinforced concrete building from full-scale forced vibration study and formulation of mathematical model. Proceedings of Fifth World Conference on Earthquake Engineering, Rome, Italy, 1973.

17. Paquet J. Etude experimentale du comportement dynamique des structures. Annales de ITBTP 1976; 200: $129-151$.

18. Argoul P, Hans S, Conti F, Boutin C. Time-frequency analysis of free oscillations of mechanical structures. Application to the identification of the mechanical behaviour of buildings under shocks. Proceedings of the System Identification and Structural Health Monitoring - COST F3 Conference, Madrid, 2000; 283 -292.

19. Ellis BR. Full-scale measurements of the dynamic characteristics of buildings in the UK. Journal of Wind Engineering and Industrial Aerodynamics 1996; 59:365-382. 